tion for the removal of dermoid cysts: "Then as soon as the white and tight coat is seen, it is to be separated from the skin and flesh by the handle of the scalpel and turned out together with its contents." His account of cataract removal, for which a handle with a needle was used, is a graphic illustration of the extraordinary refinements of Roman eye surgery: "Thereupon a needle is to be taken pointed enough to penetrate, yet not too fine; and this is to be inserted straight through the two outer tunics at a spot intermediate between the pupil of the eye and the angle adjacent to the temple, away from the middle of the cataract, in such a way that no vein is wounded."

\section{Travelling doctor}

Probably the finds from the Plemmirio site are part of a complete instrumentarium and other items from this kit, which could range from bone mallets to metal urinary catheters, remain buried at the site. If this is the case the finds are probably the belongings of a surgeon or an oculist rather than odds and ends from

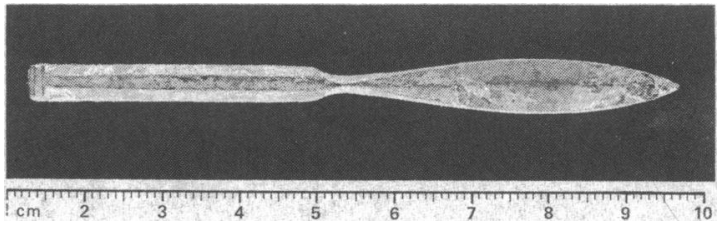

Bronze scalpel handle from wreck of Roman cargo ship

the ship's first aid box. We suggest that the doctor was travelling on board the ship as a passenger. This theory is supported by the unique nature of these finds among the 800 or so ancient wrecks that have been investigated in the Mediterranean and the consequent lack of evidence for doctors in ships' crews. These finds are not only of archaeological interest but also provide an exciting contact with someone who, although dead for almost two milleniums, had skills and concerns with which we can identify.

1 Celsus AAC. De medecina. London: Heineman, 1935-38. (Translated by W G Spencer.)

\title{
From Aretaeus to Crosby: a history of coeliac disease
}

William F Paveley

The first description of coeliac disease was probably given in the second century $\mathrm{AD}$ by Aretaeus the Cappadocian (fig 1).

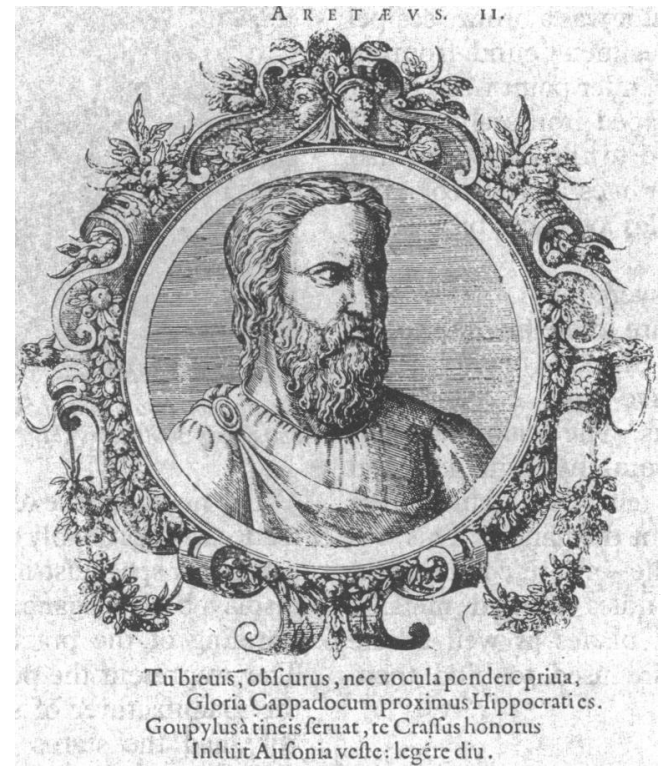

FIG I-Aretaeus the Cappadocian by $\mathcal{F}$ Sambucus, 1531-84

Aretaeus's works were translated by Francis Adams and published by the Sydenham Society in $1856 .^{.}$I paraphrase from this translation.

Derby DE7 3LG

William F Paveley, MB, general practitioner

Correspondence to:

"Heathend," 22 Station

Road, Borrowash, Derby DE7 32G.

The article is based on a presidential address given to Derby Medical Society in October 1983.
The stomach being the digestive organ, labours in digestion when diarrhoea seizes the patient. If this diarrhoea does not proceed from a slight cause of only one or two days' duration, and if, in addition, the patient's general system be debilitated by atrophy of the body, the Coeliac Disease of a chronic nature is formed.

\section{Aretaeus thought that the disease was due to:}

Atony of the heat which digests, and refrigeration of the stomach, when the food indeed is dissolved in the heat but the heat does not digest it, nor convert it into its proper chyme, but leaves its work half-finished. The food then being deprived of this operation, is changed to a state which is bad in colour, smell and consistence. For its colour is white and without bile, it has an offensive smell and is flatulent; it is liquid and wants consistence from not being completely elaborated, and from no part of the digestive process having been properly done except the commencement

\section{He describes the patient as being:}

Emaciated and atrophied, pale, feeble and incapable of performing any of his accustomed works, but if he attempts to walk, the limbs fail, the veins in the temples are prominent, for owing to wasting the temples are hollow, but also all over the body the veins are enlarged. Not only does the disease not digest properly but it does not distribute that portion in which the digestion has commenced. It appears to me, therefore, to be an affection not only of digestion but also of distribution.

Aretaeus, however, thought that this illness affected only adult patients-more common among the aged and particularly in women. Treatment consisted of rest and fasting. Pepsis was promoted by the prevention of chilling and restoration of heat. Changes in the mode of living, exercise, and massage were recommended. If these failed powerful emetics and purges were to be tried. He mentioned diet in passing. He did prescribe "drinks taken before meals, for otherwise bread is very little conducive to trim vigour." I am not suggesting that this brief reference to the ill effects of bread anticipated the findings of later workers in the unravelling of the gluten enigma. As Dowd and Walker-Smith said, "Aretaeus was wise but scarcely so prescient."

It was not until October 1887-1700 years laterthat Dr Samuel Jones Gee again drew attention to coeliac disease (fig 2). The title of his lecture was "On the Coeliac Affection." "This is the title used by Aretaeus and it has been suggested that the choice was an oblique compliment to the earlier Greek physician. Gee was the first person to note that the disease affected all ages:

There is a kind of chronic indigestion which is met with in persons of all ages, yet especially apt to affect children between one and five years old. Signs of the disease are yielded 
by the faeces, being loose, not formed but watery; more bulky than the food taken would seem to account for; pale in colour, as if devoid of bile; yeasty, frothy, an appearance probably due to fermentation; stinking, stench often very great, the food having undergone putrefaction rather than concoction.

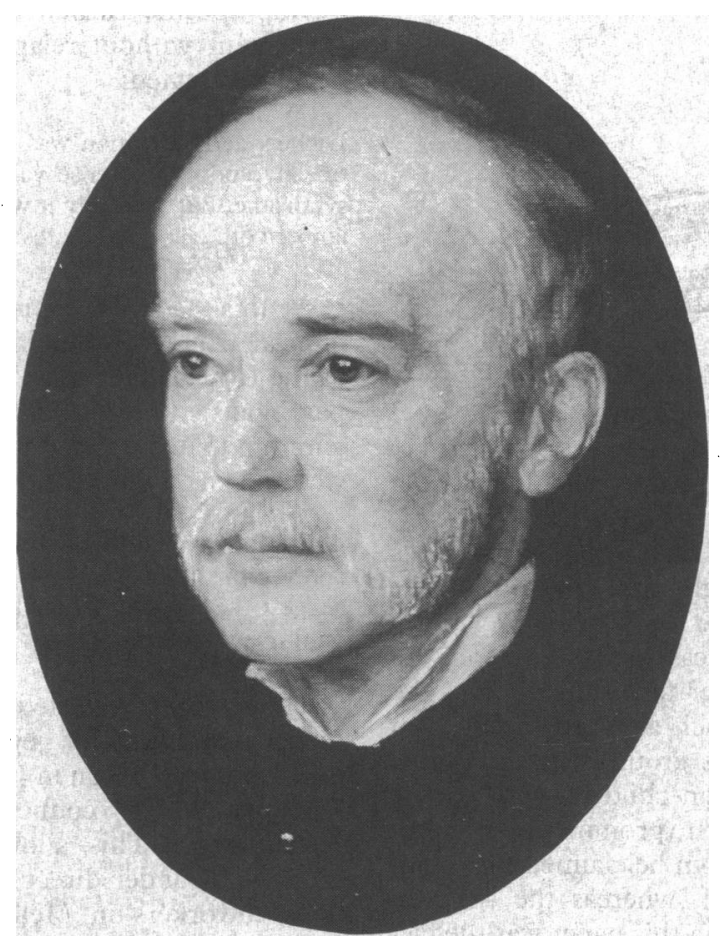

FIG 2-Samuel fones Gee by Charles Vigor c 1900

He was of the opinion that to "regulate the food is the main part of treatment." The allowance of farinaceous foods was to be small, yet he allowed rusks and bread cut thin and well toasted on both sides. He described various diets including one rather surprising one. $\mathrm{He}$ wrote:

A child who was fed upon a quart of the best Dutch mussels daily, throve wonderfully but relapsed when the season for mussels was over; next season he could not be prevailed upon to take them. This is an experiment $I$ have not yet been able to repeat. ... But if the patient can be cured at all, it must be by means of diet.

In 1889 Dr R A Gibbons wrote two articles in the Edinburgh Medical foumal on "The Coeliac Affection in Children." $\mathrm{He}$ had been introduced to the disease by Gee. Gibbons described four cases which he managed much as Gee suggested. In his account of one of his patients, aged 2 years and 8 months, there is a revealing sentence which is really a commentary on his times:

The mother, who had come from the country, had not brought the nurse and could tell me nothing about the motions, or whether the bowels were regular or not.

Postmortem examination of the bowel revealed nothing: no wasting of the mucous membrane, no ulceration, and no wasting of Lieberkühn's follicles. Gibbons stated that most children suffering from this disease died, and that the affected children had a great objection to climbing up stairs.

Dr Gibbons summarised his conclusions on the causes of the disease as follows:

That as pathological anatomy teaches us nothing regarding it, this disease depends upon a functional disturbance of the nervous supply of the liver, pancreas, glands of Brunner and follicles of Lieberkühn, possibly also of those of the stomach and salivary glands.

That as this causes a serious alteration of the digestive process, the food is too readily decomposed, and the absorption into the blood of deleterious elements produces the profound ill health from which patients attacked by this disease, suffer.

Fourteen years later, in 1903, Dr W B Cheadle published a copy of his lecture delivered at St Mary's Medical School. ${ }^{5} \mathrm{He}$ chose to call the disease "Acholia" after the apparent absence of bile in the stools. $\mathrm{He}$ thought it occurred usually in children under 5 years of age, but by far the most often in the first two years of life.

In acholia there is no jaundice; the stools are as white as those of obstructive jaundice when bile is absolutely shut out from the intestine, but there is no reabsorption of bile into the blood, or if there is it must be quickly destroyed there, for there is no staining of the tissues by its colouring matter; it does not appear in the urine.

z

He described several cases from his experience and came to the conclusion that the cause of the disease was "most obscure." He favoured Gibbons's view that the disease had a nervous origin. He ventured to suggest that the likeliest cause was a nervous inhibition due to difficult dentition, probably associated with surface chill as it seemed to occur in the "cold, spring, east wind time." His treatment was similar to that of Gee and Gibbons with the addition of lancing of the gums if the teeth were "pushing." The main importance of this paper is that for the first time it was noted that there was an excess of fat in the stools and this was proved by fat estimation.

With the publication of Herter's book, Infantilism from Chronic Intestinal Infection in 1908 a new concept of the disease was introduced. ${ }^{6} \mathrm{He}$ thought that the disease was due to an inflammation of the intestine caused by a persistence and overgrowth of intestinal flora of the nursling period, notably bacillus bifidus and bacillus infantilis, thus his term "intestinal infantilism." He observed that proteins were very well borne, fats moderately well borne and that carbohydrates were very badly tolerated.

Ten years later $G$ F Still gave three Lumleian Lectures to the Royal College of Physicians of London on the disease.? These addresses had been given for three centuries and a notable predecessor was Gee, who had lectured on "The Causes and Forms of Bronchitis and the Nature of Pulmonary Emphysema and Asthma."

As a working hypothesis Still assumed that he was dealing with a specific disease. He had little to add to the clinical picture, but his descriptions are beautifully written and sharply observed.

The most striking feature is the surprising inconsistence of the child's size with its age. What appears to be an infant little more than twelve months old, startles one by unexpectantly talking and so reveals the fact that it is at least a year or two older, perhaps three or four years older, than its appearance would suggest.

He was of the opinion that the cause of the disease was a profound digestive disturbance. He thought that the treatment had to be more or less empirical. $\mathrm{He}$ emphasised that "unfortunately, one form of starch which seems particularly liable to aggravate the symptoms, is bread." He thus repeated Aretaeus's observation without, again, appreciating its significance.

Professor Still concluded:

Gentlemen, I can only regret that I have not been able to throw more light upon the obscure problems raised by this group of cases, and the working hypothesis with which I started, that it can be pigeon-holed as one specific morbid entity, coeliac disease or intestinal infantilism, name it what you will, remains nothing more than a working hypothesis. 

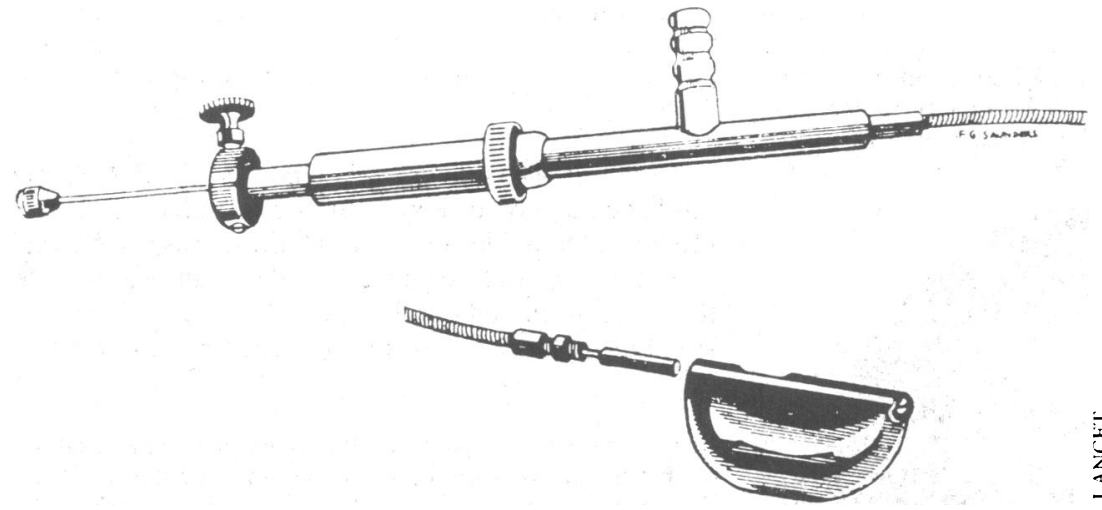

FIG 3-Margot Shiner's first duodenal biopsy tube, 1956

$\mathrm{He}$ finished with an aphorism of Heraclitus: "chruson hoi dizēmenoi gēn pollēn orussousi kai heuriskousin oligon"- "those who seek for gold dig much earth and find little."

The next landmark was in 1924 when Sidney Haas described his treatment of eight children in whom he had diagnosëd coeliac disease. ${ }^{x}$ Some years previously he had successfully treated a case of anorexia nervosa with a banana diet. He rather fancifully likened the action of the bananas to "such as is attributed to a hormone." On these tenuous grounds he thought it logical to try a banana diet on children with coeliac disease where anorexia was such a prominent symptom. He reported ten cases, of whom he claimed that eight treated were clinically cured, whereas the two untreated died. The major flaw in this paper was the fact that the jejunal pathology was not known and the diagnosis was purely on clinical grounds.

Apart from keeping the gastrointestinal tract as free from toxic products as possible by castor oil and daily colonic irrigation, Haas's treatment was purely dietary. He specifically excluded bread, crackers, potatoes, and cereals. The success of his treatment probably lay in their exclusion. Every trace of sugar was prohibited except that in protein milk prepared according to Finkelstein's formula. He excluded sucrose, which occurs in extremely ripe bananas. This sugar, he noted, was perfectly tolerated and therein, he thought, lay the crux of the matter. This belief had been strengthened when his attention had been drawn to the fact that in Puerto Rico town dwellers who ate much bread suffered from sprue, whereas farmers who lived largely on bananas never did. Gradually bananas were added to the diet, usually from four to eight a day. This treatment was continued for an indefinite period and he believed that eventually all children would react normally to most foods.

This dietary treatment of coeliac disease continued well into the 1950s under the enthusiastic influence of Haas. In the second world war children with coeliac disease were treated as a special case and were allowed extra bananas in a time of shortage.

Another more important shortage occurred during the war. In The Netherlands there was a scarcity of bread and, according to Sir Christopher Booth, Dicke, a Dutch paediatrician, observed that so called "coeliac sprue" diminished remarkably during this shortage. Apparently Dicke first noticed a possible relationship between wheat and a condition of malabsorption with a rash in a young child in 1930 . The child's mother told him that when taken off bread and biscuits the child's skin improved. When Swedish planes dropped bread into The Netherlands children with coeliac disease quickly relapsed and this helped to convince Dicke of the toxicity of wheat. Eventually he and his coworkers proved that wheat flour and not

^In a lecture to the Derby Medical Society in November 1983. wheat starch was the offending substance and that this toxic factor existed in gluten.

Despite Dicke's observations Haas still persisted with his treatment by banana diet and even as late as 1963 he stated that "practically all patients are cured by the specific carbohydrate diet, a cure which is permanent without relapse." In the same paper he perversely stated:

Dicke's demonstration was an excellent achievement scientifically and of immense value for the study of the coeliac syndrome, but clinically it was a possible disservice, since it ignored other carbohydrates as aetiological factors.

At this stage, of course, diagnosis was mainly on clinical grounds. Then in 1954 Dr Paulley, physician to the Ipswich hospitals, observed that so seldom had pathologists been confronted with biopsies of human jejunum that it was doubtful if the normal appearance was known. ${ }^{10} \mathrm{He}$ concluded:

The difficulty of obtaining satisfactory post-mortem material and the possibility of autolytic changes before death, would suggest that biopsy material is necessary to further research on this subject.

The search had started for some means of obtaining biopsy specimens of jejunal mucous membrane. I think that it all began in 1940 when Kenamore devised a biopsy forceps connected to Schindler's flexible gastroscope." This allowed gastric biopsies to be carried out under direct vision. Wood and Doig and their coworkers in Melbourne took this one stage further and designed a simple, flexible biopsy tube which could be used for gastric biopsies, without the aid of a gastroscope or an $x$ ray screen.12

This was only of use in establishing a histological diagnosis in such diffuse lesions as chronic gastritis, the atrophic gastritis of pernicious anaemia, or haemosiderosis - unless by chance an area of ulceration or malignancy was biopsied.

The sanctity of the duodenum was finally breached in 1955. Royer and his colleagues in Argentina and Margot Shiner in England separately devised their duodenal biopsy tubes based on Wood's instrument. Margot Shiner must have been unaware of the Argentine work because in January 1956 she stated that "hitherto gastric biopsy had not been extended to the duodenum."' Under fluoroscopic control the biopsy head successfully reached the duodenum in 12 out of 19 attempts (fig 3).

I think that in this article the first reference to a successful per oral jejunal biopsy. It occurred in a

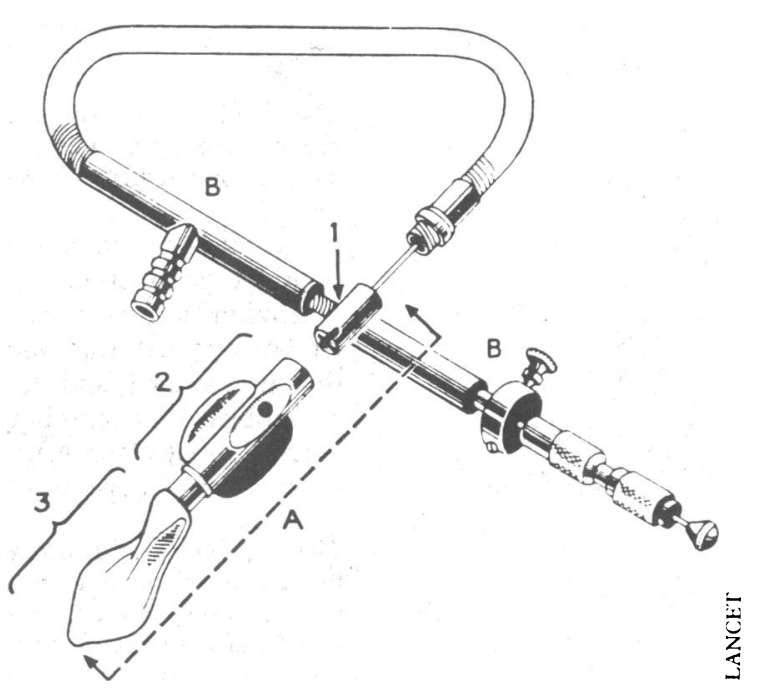

FI( 4-Margot Shiner's jejunal biopsy tube, 1956 
patient undergoing duodenal biopsy who had had a Polya gastrectomy. Shiner thought that with minor modifications biopsies could be obtained from the normally sited jejunum..$^{14}$

Once the first part of the duodenum had been reached, a rubber balloon attached to the distal end of the head piece was inflated and this, it was found, allowed the head to travel through the third and fourth parts of the duodenum and so reach the jejunum (fig 4).

Margot Shiner's biopsy tube was rather cumbersome. In Puerto Rico, where Haas had first noted the higher incidence of sprue in town dwellers as opposed to farmers whose diet contained a large proportion of bananas, Lieutenant Colonel W H Crosby of the United States army recognised the need for a more flexible instrument for obtaining jejunal biopsies for examination by the army's sprue team. Various triggering devices for initiating the action of a spring loaded knife were considered. Timers, solenoids, and magnets were rejected in favour of an air pressure mechanism, and in 1957 he and Heinz W Kugler published details of what has become known as the Crosby capsule. ${ }^{15}$
I thank Sir Christopher Booth for permission to quote from his address to the Derby Medical Society, the librarians and medical illustrators at the Derbyshire Royal Infirmary, the BMA Nuffield Library, and Margaret Barker, who translated the aphorism of Heraclitus.

1 Adams F. The extant works of Aretaeus the Cappadocian. London: London Sydenham Society, 1856:350.

2 Dowd B, Walker-Smith J. BrMed f 1974; ii:45-7.

3 Gee SJ. On the coeliac affection. St Bartholomew's Hospital Report 1888;24: 17-20.

4 Gibbons RA. The coeliac affection in children. Edinburgh Medical Journal 1889;i:321-30, 420-8.

5 Cheadle WB. Acholia. Lancet 1903;i:1497-500.

6 Herter CA. Infantilism from chronic intestinal infection: New York: Mac-

millan, 1908.
Still CF. The Lumleian lectures on coeliac disease. Lancet 1918;ii:163-6, 193-7, 227-9.

8 Haas SV. The value of the banana in the treatment of coeliac disease. Am $\mathcal{J} D$ is Child 1924;24:421-37.

9 Haas SV. Coeliac disease. NY State $f$ Med 1963 May 1:1346-50.

10 Paulley JW. Observations on the aetiology of idiopathic steatorrhoea. BrMed f 1954;ii:1318-21.

11 Kenamore B. A biopsy forceps for the flexible gastroscope. American fournal of Digestive Diseases 1940;7:539.

12 Wood IJ, Doig RK, Motteram R, Hughes A. Gastric biopsy. Lancet 1949;i: 18-21.

13 Shiner M. Duodenal biopsy. Lancet 1956;i:17-9.

14 Shiner M. Jejunal biopsy tube. Lancet 1956;i:85.

15 Crosby WH, Kugler HW. Intraluminal biopsy of the small intestine. American foumal of Digestive Diseases 1957;2:236-41.

\title{
South African gem of medical history
}

\author{
Philip Rhodes
}

Last June Dr V C Lucas reported that he had learnt about early anaesthesia and the discovery of diamonds in South Africa at the medical history museum in Johannesburg (25 June, p 1795). He found that both activities had been pioneered by William Guybon Atherstone.

I had never heard of the Adler Museum of the History of Medicine but when my wife and I were in South Africa recently we found that it was only about a mile from our hotel.

It was worth seeking out in the South African Institute for Medical Research in the grounds of the Johannesburg General Hospital because it is a gem. My experience of museums is slender, but I have seen nothing on the subject of medical history resembling the Adler Museum. General museums, such as in York

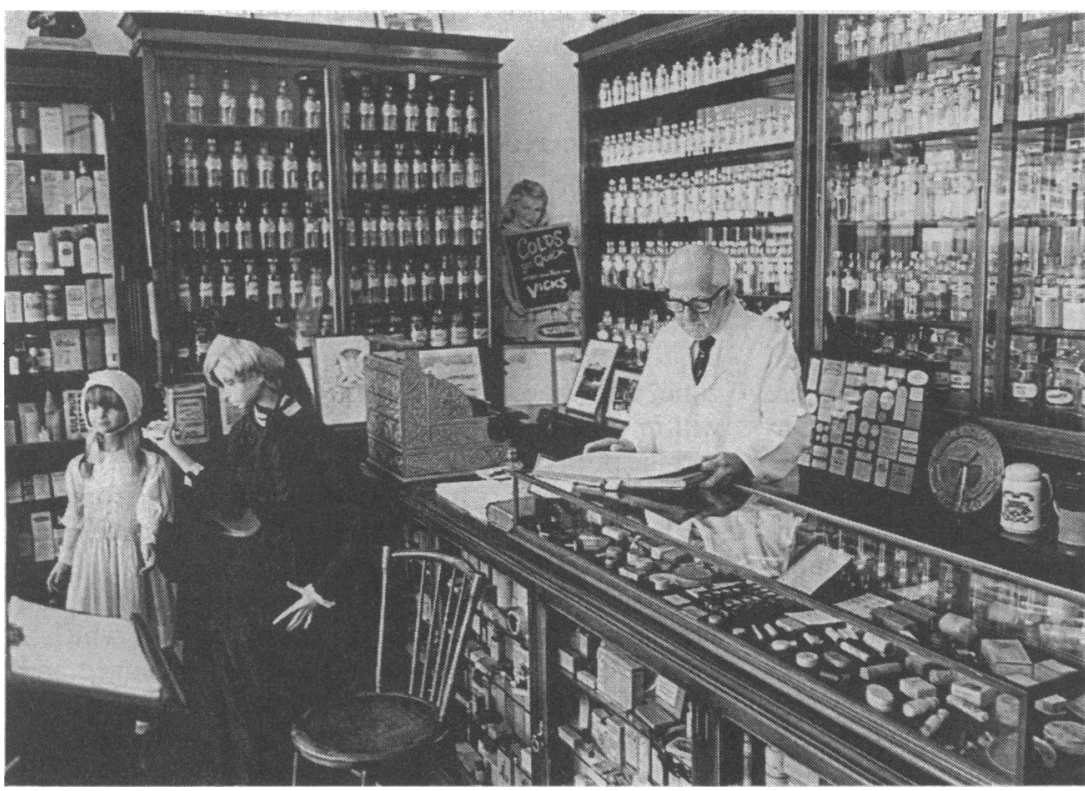

Dr Cyril Adler in his 1906 pharmacy

and in Norwich, have reconstructions from previous centuries of shops containing examples of what they purveyed, and of rooms showing all the paraphernalia with which our ancestors surrounded themselves. You feel as if you were there with them. The museums are living history, stimulating the imagination, and designed to provoke responses in the onlooker.

The Adler Museum is a work of art too. You round the corner of a house into a paved street, lit by gas lamps, with wrought iron railings and grass in front of the dentist's and the doctor's surgeries. Next door to the doctor's is a glass coach house showing off his carriage. The end of the street is mainly closed in by the chemist and druggist's (apotheker) shop. The house opposite the doctor's surgery was formerly that of the director of the South African Institute for Medical Research. There are several rooms most beautifully laid out with medical and nursing memorabilia. They are not large and overwhelming, but each is a happy and welcome surprise.

\section{Begged, borrowed, and purloined}

We walked into the house wondering what we might find. In the office was Dr Cyril Adler himself. It was embarrassing to confess that I had never heard of his museum, but he turned out to be a most welcoming and genial host.

The museum was donated to the University of Witwatersrand by its founders, the Adlers, in 1974, and at present the collection is run under the aegis of the university. Dr Adler, now the director of his own museum, with the help of his late wife, collected, begged, borrowed, bought, and perhaps purloined virtually all the items displayed. The Adlers took many years and travelled the world to get them. Like many other universities Witwatersrand can find little support, financial and otherwise, for the subject of medical history. There are no overt plans for the museum when Dr Adler dies and he is now well into his 80s. Unless the university, or the city of Johannesburg, 